\title{
Factors Affecting Tourism Destination: A Case Study in Ha Tien City, Vietnam
}

\author{
D.V. Huynh, H.T.T. Tran, T.Q. Pham, T.X. Duong, and D.T. Pham
}

\section{ABSTRACT}

On the basis of theories of tourism, services, rational choice theory and previous empirical studies, the study proposes a research framework including 6 factors affecting tourists' decisions when choosing Ha Tien as a destination to visit. The research sample was carried out by surveying by questionnaire with 100 tourists who visited Ha Tien City. Evaluation of the reliability of the scales shows that the destination information factor has not yet ensured the reliability of the scale. Regression analysis shows that there are 3 out of 6 independent factors that most influence tourists' decision to choose when choosing $\mathrm{Ha}$ Tien as a tourist destination. In which, environmental and landscape factors have the most influence on tourists' decision to choose Ha Tien as a destination. As a result, the article proposes some solutions to contribute to attracting more and more tourists to Ha Tien City.

Keywords: Destination, Ha Tien, Rational Choice Theory, Tourism, Vietnam.

Published Online: December 2, 2021

ISSN: $2736-5522$

DOI: 10.24018 / ejsocial.2021.1.6.179

D. V. Huynh*

Can Tho University, Vietnam

Email: hvda@ctu.edu.vn

H. T. T. Tran

Can Tho University, Vietnam

Email: tranthithuyhang891@gmail.com T. Q. Pham

HT Travel Company, Vietnam

Email: quangtrieucantho@ gmail.com

T. X. Duong

Tay Do University, Vietnam

Email: duongthanhxuan@ gmail.com

D. T. Pham

Can Tho City Tourism Promotion Centre, Vietnam

Email: ptdong ${ }^{@}$ cantho.gov.vn

*Corresponding Author

\section{INTRODUCTION}

Ha Tien City is a narrow strip of land located along the coast that includes all types of terrain such as lagoons, bays, plains, mountains, rivers, caves, islands, etc. forming many beautiful landscapes, which is likened to a miniature Ha Long Bay (Ha Tien City Portal, 2019). Most of the mountains in the city are popular destinations, and beaches along the Ha Tien coast are famous for their beauty, with the Hai Tac (Pirates) archipelago including many beautiful islands which have great tourism potential and are promising for developing sea and island tourism (Ha Tien City Portal, 2019). One of the famous beaches becoming an ideal tourist destination is the astounding Mui Nai Beach located on the coast of the Thailand Gulf. This is also one of the 10 beautiful landscapes of Ha Tien praised by poet Mac Thien Tu through his famous poem 'Loc Tri Village'. Ha Tien is not only blessed with many natural landscapes, but also earns a reputation for historical-cultural relics. Regarding the coastal and mountainous landscapes, Ha Tien offers many attractive tourist spots such as Mui Nai Tourist Area, Thach Dong Mountain, To Chau Mountain, Da Dung Mountain, Dong Ho Lagoon; and Binh San Mountain in terms of cultural and historical relics, etc. These tourist destinations are very suitable for the development of sightseeing tourism, convalescence and ecotourism, especially sights such as To Chau Mountain, Dong Ho Lagoon, Giang Thanh River, Mui Nai Den Mountain Tourist Area. About literary and artistic culture, there are many traditional festivals in Ha Tien such as: Lantern Festival (Tết Nguyên tiêu), founding anniversary of Tao Dan Chieu Anh Cac, Memorial Day of Mac Cuu; and artistic architectural monuments such as Mac Cuu Tomb, Phu Dung Pagoda, Thanh Hoang Communal House are also promising attractions for visitors (Tra, 2007). With such an abundant tourism potential, Ha Tien has gradually promoted its available advantages through its achievements from tourism in recent years. Mui Nai - Ha Tien tourist area was voted by the Mekong Delta Tourism Association as a typical tourist place in the Mekong Delta in 2012 (Van Linh, 2012). The infrastructure system is constantly being upgraded. Provincial road no.28 is invested to attract many tourists, thereby promoting commercial and service activities. Businesses are gradually paying more attention to this attractive field, leading to an increase in tourism service businesses in terms of quantity as well as quality. 
Nowadays, along with the development of society, tourists have higher requirements for entertainment services, therefore, their choices in tourism become even more sophisticated. Tourist destinations that respond to this demand in time will have a competitive advantage through building visitor loyalty. Current reality shows that, although the number of tourists visiting Ha Tien - Kien Giang increases every year, mainly first-time visitors make up the majority, while the number of returning visitors is not significant and only accounts for a low percentage. The reason involves many factors that make tourists hesitate to return. For example: infrastructure in some tourist spots has not been appropriately invested, traffic is difficult; transportation is not convenient; polluted environment, lack of used in daily life, etc. Therefore, in order for Ha Tien-Kien Giang tourism to develop sustainably and become a key economic sector, Kien Giang province needs to focus its resources, human resource training, and central development planning, and to propose suitable solutions to the factors affecting the development of Ha Tien - Kien Giang tourism.

\section{LITERATURE REVIEW}

According to Nguyen Xuan Hiep (2016), there are two groups of factors affecting tourists when deciding whether to choose a trip or not. The group of internal factors includes personal factors (demographic and lifestyle factors); cultural factors; psychological factors (motives, interests, attitudes, experiences). The group of external factors includes social factors (reference groups, roles, social status) and marketing factors (tourist products, tourism product prices, communication, and tourism products supply locations).

The travel intention factor is an internal force born from the psychological characteristics of the individual. The motivation pushes and maintains individual activities, helping them get on track. Different travel intentions lead to different decisions of travel destinations. According to Woodside and MacDonald (1994), tourists' experience after visiting a destination will shape their intentions for the next destination selection in the future. The consumer's attitude towards a tourist destination is the total combination of perspective, belief, experience, desires, and reactions of the consumer towards that place.

The external factors include destination attributes. Among destination attributes, destination image is the key factor and has the greatest influence on tourists' decision of destination selection. According to Lawson and Baud-Bovy (1977), the destination image is the representation of all knowledge, impressions, prejudices, and feelings of an individual or a group of people towards an object or a specific place. Marketing factors include tour price factors, tour agency, and media. The reference group includes friends, family, and relatives, who have an important influence on tourists' decision to choose a destination. About factors of trip characteristics, Mathieson and Wall (1982) emphasized that factors of trip characteristics affect different aspects of tourist behavior of destination selection.

Research by Lin et al. (2007) on "Examining the role of cognitive and affective image in predicting choice across natural, developed, and theme-park destinations" was carried out in Taiwan. The author has synthesized related theories to propose a research model. The study assesses the influence of destination image groups, including (1) destination perception image, (2) emotional image to destination, (3) general image, (4) choice of destination. The results of the analysis of 1,020 surveyed tourists show that both cognitive images and emotional images have an influence on tourists' choice of destinations. However, the influences of these two groups of factors are different for each type of destination with different characteristics.

Research by Som, Marzuki et al. (2012) about "Factors influencing visitors' revisit behavioral intentions: A case study of Sabah, Malaysia" was carried out to determine the factors affecting tourists' return to Sabah. The subjects of this study are international tourists. Research results show the importance of factor analysis for destination attributes determined in the following order: (1) image of the destination, (2) modern environment, (3) natural nature and time, (4) destination image is an important destination attribute that makes visitors return to a tourist site in Sabah. The results of factor analysis on tourism motivation show that the importance of each factor in order is: (1) leisure and entertainment, (2) expanding relationships, (3) social values, (4) fulfilling a wish, (5) escaping from daily life. In particular, the element of leisure and entertainment is the most important motivation for tourists to return to Sabah.

Researching on "Analysis of factors affecting tourist satisfaction when traveling to Kien Giang", Luu Thanh Duc Hai et al. (2011) used the theory of service quality to build a research model; their research methodology is deductive. The purpose of the study is to evaluate the influence of factors including (1) Amenities of accommodation, (2) Good means of transportation, (3) Attitude of tour guides, (4) Appearance of tour guide, (5) Infrastructure for tourism leading to customer satisfaction about the quality of tourism services in Kien Giang. Analysis results from 295 surveyed tourists show that visitor satisfaction is affected by the above factors. In particular, the attitude and form factor of the tour guide strongly influences the satisfaction of tourists, followed by means of transport, infrastructure for tourism, and amenities of accommodation facilities.

Results from research by Luu Thanh Duc Hai (2014) on "Analysis of factors affecting tourist satisfaction 
about the quality of tourism services in Tien Giang" show that in the range of 1,384 tourists surveyed to Tien Giang, including 588 international visitors and 796 domestic tourists, visitor satisfaction is related to 3 factors: (1) Physical conditions for tourism and security issues, (2) Staff quality and service price, (3) Foodservice quality, by 17 observed variables. Based on the results of exploratory factor analysis and binary regression analysis, the three components mentioned above have a causal relationship with visitor satisfaction. In which the factor of foodservice quality has the strongest impact.

Phung Vu Bao Ngoc (2014) researched "The influence of destination on tourist loyalty: a case study of tourist destinations in Ho Chi Minh City." Based on interviews with 360 tourists by convenient sampling method, the author used software to analyze the factors affecting the loyalty of tourists. The analysis results show that the factors affecting customer loyalty include entertainment, landscape environment, economic and political environment, infrastructure, food, and shopping.

A study by Nguyen Xuan Hiep (2016) on "Factors affecting tourists' decision to choose destinations: The case of destinations in Ho Chi Minh City." The study explores and measures the factors affecting the tourists' decision to choose Ho Chi Minh City as a destination, by combining qualitative and quantitative research methods. Data were collected on 615 domestic and international tourists who have visited Ho Chi Minh City. The research results show that the factors affecting tourists' decision to choose Ho Chi Minh City as a destination include: (1) Travel intention, (2) Destination image, (3) Information source about the destination. In particular, the factor "information source about the destination" has the strongest influence on the tourists' choice of destination.

Through literature review, the author has inherited the tourism motivation factor of Nguyen Xuan Hiep (2016) on "Factors affecting tourists' decision to choose destinations: The case of destination Ho Chi Minh City," factors of environment and landscape, infrastructure, cuisine, and shopping of Phung Vu Bao Ngoc (2014) on "Destination's influence on tourist's loyalty: a case study of tourist destination Citadel Ho Chi Minh City," and the service price factor of Luu Thanh Duc Hai (2014) on "Analysis of factors affecting tourist satisfaction about the quality of tourism services in Tien Giang." Thereby, the author finds out the development direction for the topic, as well as inherits and promotes the researches to study the factors affecting tourists' choice of $\mathrm{Ha}$ Tien as a travel destination following: infrastructure, landscape environment, destination information, food and shopping, travel intention, and decision to choose a destination.

\section{RESEARCH METHODS}

Secondary data are collected through reports of Ha Tien City People's Committee and the Internet. Using published data from domestic and international studies, the author has pointed out the variables that affect tourists' decision to choose a destination to visit or travel in Ha Tien city. The purpose of this preliminary study is to introduce and discuss in order to exploit the variables affecting the decision of tourists to choose places to visit and travel in Ha Tien, Kien Giang province.

Based on related studies, the author builds a research model consisting of 6 factors. The author then conducts interviews with experts who have experience in the field of tourism to determine the factors affecting the decision of tourists to choose a tourist destination in Ha Tien, thereby, discusses with experts about the interview questionnaire, and conducts pilot interviews with 10 tourists to complete the questionnaires, and followed by the official research.

Following the sample calculation formula according to Tabachnick and Fidell (2007):

$\mathrm{N}=8 * \operatorname{var}+50$

"N" is the sample size, "var" is the number of independent variables. So, $\mathrm{N}=100$ samples with var $=6$.

On the theoretical basis of consumer behavior and related studies, the author builds a scale of tourists' decision on choosing destinations to visit and travel in Ha Tien city. The scale is designed according to the Likert scale as follows: (1) Strongly disagree, (2) Disagree, (3) Neutral, (4) Agree, (5) Strongly agree. Through the scale, the author builds a survey to find out the factors affecting the choice of Ha Tien as a tourist destination (Table I). 
European Journal of Humanities and Social Sciences www.ej-social.org

TABLE I: TABLE OF SCALE CONSTRUCTION FOR TOURISTS's DECISION ON THE CHOICE OF PLACES TO VISIT AND TRAVEL IN HA

\begin{tabular}{|c|c|c|}
\hline \multicolumn{3}{|c|}{ TIEN CITY } \\
\hline Factor & Description & Source \\
\hline \multicolumn{3}{|c|}{ INFRASTRUCTURE } \\
\hline INFR1 & $\begin{array}{l}\text { Transportation system in Ha Tien is } \\
\text { convenient. }\end{array}$ & $\begin{array}{c}\text { Nguyen Xuan Hiep (2016), Nguyen } \\
\text { Phung Bao Ngoc (2014) }\end{array}$ \\
\hline INFR2 & $\begin{array}{c}\text { The system of hotels and motels in } \mathrm{Ha} \\
\text { Tien has good quality. }\end{array}$ & Nguyen Xuan Hiep (2016) \\
\hline INFR3 & $\begin{array}{c}\text { Information and communication } \\
\text { services in Ha Tien developed. }\end{array}$ & Nguyen Xuan Hiep (2016) \\
\hline \multicolumn{3}{|c|}{$\begin{array}{c}\text { ENVIRONMENT AND } \\
\text { LANDSCAPES } \\
\end{array}$} \\
\hline ENVR1 & \multirow{4}{*}{$\begin{array}{c}\text { There are many landscapes to explore } \\
\text { when coming to Ha Tien. } \\
\text { The environment in Ha Tien is less } \\
\text { polluted with dust and noise. } \\
\text { Ha Tien has beautiful beaches. } \\
\text { Ha Tien has many historical and cultural } \\
\text { relics. }\end{array}$} & $\begin{array}{c}\text { Nguyen Xuan Hiep (2016), Nguyen } \\
\text { Phung Bao Ngoc (2014) }\end{array}$ \\
\hline ENVR2 & & Nguyen Xuan Hiep (2016) \\
\hline ENVR3 & & Expert interviews \\
\hline ENVR4 & & Expert interviews \\
\hline INFO & \multicolumn{2}{|l|}{$\begin{array}{c}\text { INFORMATION ABOUT THE } \\
\text { DESTINATION }\end{array}$} \\
\hline INFO1 & $\begin{array}{l}\text { You know about Ha Tien based on } \\
\text { experience. }\end{array}$ & Nguyen Xuan Hiep (2016) \\
\hline INFO2 & $\begin{array}{l}\text { You know about Ha Tien from friends, } \\
\text { colleagues, or relatives. }\end{array}$ & Nguyen Xuan Hiep (2016) \\
\hline INFO3 & $\begin{array}{l}\text { You know about Ha Tien from the } \\
\text { media. }\end{array}$ & Nguyen Xuan Hiep (2016) \\
\hline INFO4 & $\begin{array}{l}\text { You know about Ha Tien from the } \\
\text { introduction of travel agencies. }\end{array}$ & Interview with experts \\
\hline CSNSP & \multicolumn{2}{|l|}{ CUISINE AND SHOPPING } \\
\hline CSNSP1 & \multirow{4}{*}{$\begin{array}{l}\text { Cuisine in Ha Tien is very diverse. } \\
\text { Ha Tien has many unique and delicious } \\
\text { dishes. } \\
\text { Ha Tien has a variety of shopping } \\
\text { activities. } \\
\text { Ha Tien has many shopping items and } \\
\text { souvenirs. }\end{array}$} & $\begin{array}{c}\text { Nguyen Xuan Hiep (2016), Luu Thanh } \\
\text { Duc Hai (2014) }\end{array}$ \\
\hline CSNSP2 & & $\begin{array}{c}\text { Nguyen Xuan Hiep (2016), Luu Thanh } \\
\text { Duc Hai (2014) }\end{array}$ \\
\hline CSNSP3 & & $\begin{array}{c}\text { Nguyen Xuan Hiep (2016), Nguyen } \\
\text { Phung Bao Ngoc (2014) }\end{array}$ \\
\hline CSNSP4 & & Nguyen Xuan Hiep (2016) \\
\hline INTT & \multicolumn{2}{|l|}{ TRAVEL INTENTION } \\
\hline INTT1 & \multirow{2}{*}{$\begin{array}{l}\text { You come to Ha Tien for entertainment. } \\
\text { You come to Ha Tien to visit and } \\
\text { explore. }\end{array}$} & Nguyen Xuan Hiep (2016) \\
\hline INTT2 & & Nguyen Xuan Hiep (2016) \\
\hline INTT3 & $\begin{array}{c}\text { You come to Ha Tien to exchange, to } \\
\text { learn, or to look for business } \\
\text { opportunities. }\end{array}$ & Nguyen Xuan Hiep (2016) \\
\hline INTT4 & $\begin{array}{l}\text { You come to Ha Tien to go to another } \\
\text { tourist destination easily from there. }\end{array}$ & Nguyen Xuan Hiep (2016) \\
\hline PRICE & SERVICE PRICE & \\
\hline PRICE1 & \multirow{2}{*}{$\begin{array}{c}\text { Food prices in Ha Tien are reasonable. } \\
\text { The price of souvenirs in Ha Tien is } \\
\text { reasonable. }\end{array}$} & Luu Thanh Duc Hai (2014) \\
\hline PRICE2 & & Luu Thanh Duc Hai (2014) \\
\hline PRICE3 & $\begin{array}{c}\text { The price of transport services in } \mathrm{Ha} \\
\text { Tien is affordable. }\end{array}$ & Luu Thanh Duc Hai (2014) \\
\hline PRICE4 & $\begin{array}{l}\text { Ticket prices at tourist attractions are } \\
\text { suitable for tourists' budgets. }\end{array}$ & $\begin{array}{c}\text { Nguyen Xuan Hiep (2016), Luu Thanh } \\
\text { Duc Hai (2014) }\end{array}$ \\
\hline DECIS & $\begin{array}{c}\text { DECISION ON CHOOSING } \\
\text { DESTINATION } \\
\end{array}$ & \\
\hline DECIS1 & $\begin{array}{l}\text { You have carefully considered before } \\
\text { choosing Ha Tien to visit. }\end{array}$ & Nguyen Xuan Hiep (2016) \\
\hline DECIS2 & $\begin{array}{l}\text { Choosing Ha Tien for traveling is a } \\
\text { completely right decision. } \\
\text { You decide to continue choosing } \mathrm{Ha}\end{array}$ & Nguyen Xuan Hiep (2016) \\
\hline DECIS3 & $\begin{array}{c}\text { Tien for traveling when given the } \\
\text { opportunity. }\end{array}$ & Nguyen Phung Bao Ngoc (2014) \\
\hline DECIS4 & $\begin{array}{l}\text { You will recommend Ha Tien to friends } \\
\text { and relatives for visiting and traveling. }\end{array}$ & Nguyen Xuan Hiep (2016) \\
\hline
\end{tabular}

Preliminary assessment of the scale reliability and scale value is done by the method of Cronbach's Alpha coefficient through the software SPSS 20.0 in order to screen and remove items that do not meet the standard of reliability. According to Hoang Trong and Chu Nguyen Mong Ngoc (2008, pp. 257-258) and many researchers, they can be used when Cronbach's Alpha coefficient has a value from 0.6. However, if Cronbach's Alpha coefficient is too large (0.95), collinearity will occur in the measurement, which means that many variables in the scale do not differ at all (Tho, 2011, pp. 350-351). However, besides Cronbach's 
Alpha coefficient, the item-total correlation is also used because Cronbach's Alpha coefficient does not indicate which item should be removed and which should be kept; Accordingly, variables with total correlation $<0.3$ will be removed (Tho, 2011).

The process of linear regression analysis is carried out through the following steps:

Step 1: Checking the correlation between the independent variables, and with the dependent variable, through the correlation coefficient matrix. Accordingly, the condition for regression analysis is having a correlation between the independent variables and the dependent variable. However, if the correlation coefficient is $>0.85$, the role of the independent variables should be considered because multicollinearity may occur (one independent variable can be explained by another).

Step 2: Building and testing the regression model

$\mathrm{Y}=\beta 1 \mathrm{X} 1+\beta 2 \mathrm{X} 2+\beta 3 \mathrm{X} 3+\beta 4 \mathrm{X} 4+\ldots+\beta \mathrm{KXk}$

This is done through the following procedures:

Selecting the variables to be included in the regression model by Enter - SPSS 20.0 to handle all the included variables at the same time.

The fit of the model is evaluated by the coefficient of determination R2 (R Square). However, R2 has the characteristic of increasing when adding more independent variables to the model, while it is not always true that the model with more independent variables is better suited to the data set. Therefore, the adjusted R2 (Adjusted R Square), which does not depend on the number of variables added to the model, is used instead of R2 to evaluate the fit of the multiple regression model.

Testing the fit of the model to choose the optimal model by using ANOVA analysis method to test the hypothesis H0: (there is no linear relationship between the dependent variable and the set of independent variables $\beta 1=\beta 2=\beta 3=\beta \mathrm{K}=0)$.

If the F statistic has a very small Sig $(<0.05)$, then hypothesis $\mathrm{H} 0$ is rejected; we conclude that the set of independent variables in the model can explain the variation of the dependent variable. That is, the model built fits the data set and can be used.

Determining the coefficients of the regression equation, which are partial regression coefficients $\beta \mathrm{k}$ that measure the mean change of the dependent variable when the independent variable Xk changes by one unit, while the other independent variables are unchanged. However, the magnitude of $\beta \mathrm{k}$ depends on the units of measure of the independent variables, so comparing them directly doesn't make sense. Therefore, to compare the regression coefficients with each other in order to determine the significance (explanation) of the independent variables on the dependent variable, the measures of all independent variables are expressed by the beta unit of measure of Std. deviation.

Step 3: Checking for violation of regression assumptions

The regression model is considered suitable for the study population when it does not violate the assumptions. Therefore, after constructing the regression equation, it is necessary to check necessary assumption violations as follows:

There is a linear relationship between the independent variables and the dependent variable.

The residuals of the dependent variable are normally distributed.

The variance of the error does not change.

There is no correlation between the residuals (independence of errors).

There is no correlation between the independent variables (no multicollinearity).

In which, the tool to test the assumption of the linear relationship is the standardized residual Scatterplot showing the correlation between the standardized residual value and the standardized predicted value.

The tool to test the assumption that the residuals are normally distributed is the Histogram or P-P plot.

The tool to test the assumption that the dependent variable has a constant variance is the scatter plot of the residuals and the predicted value or the Spearman's rho test.

The tool used to test the assumption that there is no correlation between the residuals is the D statistic (Durbin - Watson) or the standardized residual Scatter plot.

The tool used to detect the existence of multicollinearity is tolerance or the variance inflation factor (VIF). According to Hoang Trong and Chu Nguyen Mong Ngoc (2008, pp. 217-218), VIF > 10 is a sign of multicollinearity in general; meanwhile, according to Nguyen Dinh Tho (2011, p. 497), when VIF > 2, it is necessary to pay attention about multicollinearity.

On the basis of related theories on tourism, service quality, behavioral theory, and empirical studies of the authors Nguyen Xuan Hiep (2016), Phung Vu Bao Ngoc (2014), Luu Thanh Duc Hai et al. (2014), the author proposes a framework to study the factors affecting the tourists' decision to choose a destination in Ha Tien city to visit or travel, specifically shown in Fig. 1: 


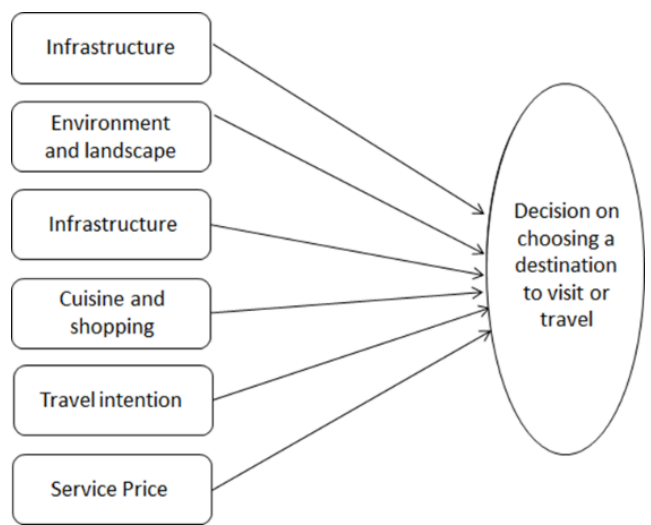

Fig. 1. Research framework on factors affecting tourists' decision to choose a tourist destination.

To measure the factors in the research framework on the tourists' decision to choose a tourist destination when coming to Ha Tien, a 5-level Likert scale is used for the survey variables: (1) Not influential at all, (2) Not influential, (3) Normal, (4) Influential, (5) Very influential.

INFR factors include 3 observed variables: (x1) Transportation system, (x2) Good quality accommodation system, (x3) Information and communication services.

ENVR factors include 4 observed variables: (x1) Many landscapes to explore, (x2) Less polluted environment, (x3) Beautiful beaches, (x4) Historic and cultural relics.

INFO factors include 4 observed variables: (x1) Based on experience, (x2) From friends, colleagues, relatives, (x3) From media, (x4) From introduction of travel agencies.

CSNSP factor includes 4 observed variables: (x1) Rich cuisine, (x2) Many unique and delicious dishes, (x3) Diverse shopping activities, (x4) Many shopping items and souvenirs.

INTT factors include 4 observed variables: (x1) Travel for entertainment, (x2) Travel for sightseeing and discovery, (x3) Travel for exchange, learning, and looking for business opportunities.

PRICE factors include 4 observed variables: (x1) Food prices, (x2) Prices of souvenirs, (x3) Prices of transportation services, $(\mathrm{x} 4)$ Prices of sightseeing tickets at tourist attractions.

\section{RESEARCH FINDINGS}

\section{A. Basic Information of the Study Sample}

Based on the actual survey, the sample includes (41\%) men and (59\%) women. Those aged 18 to 30 accounted for $13 \%$, from 31 to 45 accounted for $30 \%$, from 46 to 60 accounted for $37 \%$, and those aged 60 and over accounted for $20 \%$. Tourists working in public sectors accounted for (45\%), in business and trade accounted for (29\%), students accounted for only (9\%), and other occupations accounted for (14\%). Surveyed tourists having income from 5 to 10 million accounted for $(61 \%)$, those having income over 10 million accounted for $(23 \%)$, the rest $16 \%$ are those having income under 5 million.

\section{B. Checking the Measurement Model and Evaluating the Reliability of the Scale}

Preliminary assessment of the reliability and value of the scale is done by the method of reliability Cronbach's Alpha coefficient through the processing software SPSS 20.0 to screen and remove observed variables that do not meet the reliability standards (Table II).

TABLE II: CRONBACH'S ALPHA COEFFICIENT OF THE SCALE

\begin{tabular}{cccc}
\hline \hline Factor & Variable & Deleted Variable & Cronbach's Alpha \\
\hline INFR & 5 & 1 & 0.600 \\
ENVR & 4 & 1 & 1 \\
INFO & 4 & 3 & 0.805 \\
INTT & 3 & 1 & 0.746 \\
PRICE & 4 & 1 & 0.526 \\
CSNSP & 4 & 1 & 0.761 \\
DECIS & 4 & & 0.755 \\
\hline \hline
\end{tabular}

INFR: The Cronbach's Alpha coefficient is 0.6, and the corrected item-total correlation is greater than 0.3 because the group of infrastructure factors is reliable. But the variable of "transportation system in Ha Tien is convenient" has Cronbachs Alpha coefficient of $0.060>0.6$, so in this case, the variable of "transportation system in Ha Tien is convenient" is eliminated.

ENVR: The Cronbach's Alpha coefficient is $0.805>0.6$, and the corrected item-total correlation is both 
greater than 0.3 because the group of factors on the ENVR factor is reliable. But with the variable of "Ha Tien has many historical and cultural relics," the Cronbach's Alpha coefficient is $0.953>0.805$, so we exclude the variable of "Ha Tien has many historical and cultural relics" in this case.

INFO: The Cronbach's Alpha coefficient is $0.746>0.6$, and the corrected item-total correlation is greater than 0.3 , so the group of factors on destination information is reliable. But with the variable of "you know of Ha Tien based on experience," the coefficient of Cronbach's Alpha if item deleted is $0.883>0.746$, so we exclude this item.

INTT: The Cronbach's Alpha coefficient is 0.526, and the corrected item-total correlation are all less than 0.3 for all variables of this group of factors, so these three variables are excluded: "You come to Ha Tien for entertainment purposes," "You come to Ha Tien to visit and explore," "You come to Ha Tien to exchange, learn and look for business opportunities."

CSNSP: The Cronbach's Alpha coefficient is 0.755 , and the corrected item-total correlation is greater than 0.3. But in this group of factors, the variable of "Ha Tien has rich cuisine" has the corrected item-total correlation less than 0.3 and Cronbach's Alpha if item deleted is $0.899>0.755$, so we exclude the variable of "Ha Tien has rich cuisine."

PRICE: The corrected item-total correlations are all greater than 0.3, and the Cronbach's Alpha if item deleted is less than 0.761 . However, for the variable of "the prices of entrance tickets at tourist destinations are suitable for tourists' budgets," the corrected item-total correlation and the coefficient of Cronbach's Alpha are not reasonable, so we exclude this item in the service price factors.

DECIS: The corrected item-total correlation is greater than 0.3. Only the variable of "decision on choosing Ha Tien for traveling is a completely correct decision" has the Cronbach's Alpha coefficient if item deleted is $0.986>0.953$, so we will exclude this item in the factors of DECIS.

\section{Assessing the Level of Agreement of the Factors Affecting the Decision to Choose Ha Tien to Visit}

In order to objectively evaluate the following factors: infrastructure, environment and landscape, information about the destination, cuisine and shopping, service price, travel intention, decision on choosing a destination through the level of agreement of tourists when deciding to choose Ha Tien to visit, the author conducts a survey to assess the level of agreement of tourists through survey questionnaires.

The infrastructure

Infrastructure plays an important role in the quality of tourism services. Infrastructure here is understood as a transportation system, system of hotels and motels, and information and communication services.

TABLE III: THE LEVEL OF AGREEMENT OF TOURISTS ON ENVIRONMENT AND LANDSCAPE (N = 100 VISITORS)

\begin{tabular}{|c|c|c|c|c|c|}
\hline \multirow{2}{*}{ Infrastructure } & \multicolumn{5}{|c|}{ Level of agreement (\%) } \\
\hline & 1 & 2 & 3 & 4 & 5 \\
\hline Transportation system in Ha Tien is convenient. & 2 & 5 & 23 & 29 & 41 \\
\hline The system of hotels and motels in Ha Tien has good quality. & 1 & 0 & 18 & 28 & 53 \\
\hline Information and communication services in Ha Tien develop & 3 & 2 & 24 & 34 & 37 \\
\hline
\end{tabular}

(Source: Results from survey)

The results of Table III show that over $70 \%$ of respondents agree that Ha Tien has a convenient transportation system, a good quality system of hotels and motels, and developed information and communication services. However, there are still a few people who disagree.

Environment and landscape

Factors of environment and landscape are shown through the fact that Ha Tien has many spots to explore, the less polluted environment, beautiful beaches, and many historical and cultural relics.

TABLE IV: THE LEVEL OF AGREEMENT OF TOURISTS ON INFRASTRUCTURE FACTORS ( $=100$ VISITORS)

\begin{tabular}{|c|c|c|c|c|c|}
\hline \multirow{2}{*}{ Environment and landscape } & \multicolumn{5}{|c|}{ Level of Agreement (\%) } \\
\hline & 1 & 2 & 3 & 4 & 5 \\
\hline There are many landscapes to explore when coming to Ha Tien. & 0 & 1 & 20 & 29 & 50 \\
\hline $\begin{array}{c}\text { The environment in Ha Tien is less polluted with dust and } \\
\text { noise. }\end{array}$ & 0 & 2 & 17 & 27 & 54 \\
\hline Ha Tien has beautiful beaches. & 0 & 3 & 17 & 26 & 54 \\
\hline Ha Tien has many historical and cultural relics. & 0 & 0 & 7 & 62 & 31 \\
\hline
\end{tabular}

(Source: Results from survey)

The results of Table IV show that $79 \%$ of respondents think that Ha Tien has many landscapes to explore; $80 \%$ of respondents chose that Kien Giang has beautiful beaches and $93 \%$ of those said that there are many historical and cultural relics. However, there are still $19 \%$ of respondents who do not agree that Ha Tien has an environment less polluted with dust and noise.

Information about the destination 
European Journal of Humanities and Social Sciences www.ej-social.org

Factors of information about the destination are shown by the fact that tourists know Ha Tien based on experience, through friends, colleagues, relatives, or the media.

TABLE V: THE LEVEL OF AGREEMENT OF TOURISTS ON FACTORS OF INFORMATION ABOUT THE DESTINATION (N = 100 VISITORS)

\begin{tabular}{|c|c|c|c|c|c|}
\hline \multirow{2}{*}{ Information about the destination } & \multicolumn{5}{|c|}{ Level of Agreement (\%) } \\
\hline & 1 & 2 & 3 & 4 & 5 \\
\hline You know about Ha Tien based on experience. & 1 & 2 & 23 & 44 & 30 \\
\hline You know about Ha Tien from friends, colleagues, relatives. & 0 & 1 & 20 & 30 & 49 \\
\hline You know about Ha Tien from media. & 0 & 3 & 17 & 27 & 53 \\
\hline $\begin{array}{c}\text { You know about Ha Tien from the introduction of travel } \\
\text { agencies. }\end{array}$ & 1 & 1 & 25 & 34 & 39 \\
\hline
\end{tabular}

(Source: Results from survey)

The results of Table V show that $74 \%$ of the respondents agree that tourists know about Ha Tien based on experience, but $26 \%$ of the respondents disagree. $79 \%$ of the respondents agree that tourists know about Ha Tien from friends, colleagues, relatives, but $21 \%$ of the respondents disagree. $80 \%$ of the respondents agree that tourists know about Ha Tien from the media, but $20 \%$ disagree. There are $73 \%$ of the respondents agree that tourists know about Ha Tien from the introduction of travel agencies, but $27 \%$ of the respondents disagree.

Cuisine and shopping

In order to attract tourists to Ha Tien, cuisine and shopping is an important factor that can retain tourists, which is reflected in Ha Tien's rich cuisine, many unique dishes, and many shopping activities with many shopping items and souvenirs.

TABLE VI: THE LEVEL OF AGREEMENT OF TOURISTS ON FACTORS OF CUISINE AND SHOPPING (N=100 VISITORS)

\begin{tabular}{cccccc} 
Cuisine and shopping & \multicolumn{5}{c}{ Level of Agreement (\%) } \\
\cline { 2 - 6 } & \multicolumn{1}{c}{1} & 2 & 3 & 4 & 5 \\
\hline Ha Tien has rich cuisine. & 1 & 2 & 23 & 44 & 30 \\
Ha Tien has many unique and delicious dishes. & 0 & 1 & 20 & 29 & 50 \\
Ha Tien has a variety of shopping activities. & 0 & 2 & 17 & 27 & 54 \\
Ha Tien has many shopping items and souvenirs. & 1 & 1 & 25 & 34 & 39 \\
\hline \hline
\end{tabular}

(Source: Results from survey)

The results of Table VI show that $74 \%$ of the respondents agree and $26 \%$ of the respondents disagree that $\mathrm{Ha}$ Tien has a rich cuisine. $79 \%$ of the respondents agree and $21 \%$ of the respondents disagree that Ha Tien has many unique and delicious dishes. $81 \%$ of the respondents agree and $19 \%$ of the respondents disagree that Ha Tien has diversified shopping activities. $73 \%$ of the respondents agree and $27 \%$ of the respondents disagree that Ha Tien has many shopping items and souvenirs.

Travel intention

Travel intention is shown by the fact that tourists come to Ha Tien for entertainment, sightseeing, tourism, discovery, exchange, learning, or looking for business opportunities.

\begin{tabular}{|c|c|c|c|c|c|}
\hline \multirow{2}{*}{ Travel intention } & \multicolumn{5}{|c|}{ Level of Agreement (\%) } \\
\hline & 1 & 2 & 3 & 4 & 5 \\
\hline You come to Ha Tien for entertainment. & 1 & 2 & 23 & 44 & 30 \\
\hline You come to Ha Tien to visit and explore. & 0 & 1 & 20 & 29 & 50 \\
\hline $\begin{array}{c}\text { You come to Ha Tien to exchange, learn or look for } \\
\text { business opportunities. }\end{array}$ & 0 & 2 & 32 & 25 & 41 \\
\hline
\end{tabular}

(Source: Results from survey)

The results of Table VII show that $74 \%$ of the respondents agree that visitors come Ha Tien for entertainment, and $26 \%$ of the respondents disagree. $79 \%$ of the opinions agree that visitors come to Ha Tien to visit and explore, but $21 \%$ of the respondents disagree. $66 \%$ of the respondents agree that visitors come to Ha Tien to exchange, learn, or find business opportunities. In fact, most of the reasons for tourists to visit and travel are mainly for entertainment and relaxing after stressful working time. On the other hand, Ha Tien (Kien Giang) is located in the tourist linkage chain of Can Tho, Dong Thap, An Giang, and especially Cambodia, so most tourists choose Ha Tien as a destination in their travel itinerary.

Service price

Service price is one of the factors that bring satisfaction to tourists when traveling. Service price is shown through the criteria of food prices, prices of souvenirs, prices of transportation services, and prices of sightseeing tickets at tourist attractions.

With favorable natural conditions, Ha Tien has many specialties from the sea to offer. Therefore, Ha Tien has an extremely rich cuisine with many delicious and unique dishes from crabs, squid, sea fish, etc. There are many tourist products such as pearls, pepper, etc. 


\begin{tabular}{ccccccc}
\hline Service price & \multicolumn{5}{c}{ Level of Agreement (\%) } \\
\cline { 3 - 7 } & & 1 & 2 & 3 & 4 & 5 \\
Food prices in Ha Tien are reasonable. & & 0 & 1 & 20 & 29 & 50 \\
Prices of souvenirs in Ha Tien are reasonable. & & 0 & 3 & 17 & 27 & 53 \\
The price of transportation services in Ha Tien is \\
$\begin{array}{c}\text { affordable. } \\
\text { The prices of sightseeing tickets at tourist }\end{array}$
\end{tabular}

(Source: Results from survey)

The results of Table VIII show that $79 \%$ of the respondents agree and $21 \%$ disagree that food prices in Ha Tien are appropriate. $80 \%$ of the respondents agree and $20 \%$ disagree that the prices of souvenirs in Ha Tien are reasonable. $79 \%$ of the respondents agree and $21 \%$ disagree that the price of transportation services in Ha Tien is affordable. Up to $92 \%$ of the respondents agree and only $8 \%$ disagree that the prices of sightseeing tickets at tourist attractions are suitable for tourists' budgets.

Decision on choosing a destination

The tourists' decision to choose Ha Tien as a destination is carefully considered decision before choosing, a completely right decision, or decision to continue choosing Ha Tien for traveling when given the opportunity.

TABLE IX: THE LEVEL OF AGREEMENT OF TOURISTS ON FACTORS OF DECISION ON CHOOSING A DESTINATION (N = 100 VISITORS)

\begin{tabular}{|c|c|c|c|c|c|}
\hline \multirow{2}{*}{ Decision on choosing a destination } & \multicolumn{5}{|c|}{ Level of Agreement (\%) } \\
\hline & 1 & 2 & 3 & 4 & 5 \\
\hline $\begin{array}{c}\text { You have carefully considered before choosing Ha Tien to } \\
\text { visit. }\end{array}$ & 0 & 1 & 20 & 29 & 50 \\
\hline $\begin{array}{l}\text { The decision to choose Ha Tien for traveling is a completely } \\
\text { right decision. }\end{array}$ & 0 & 2 & 17 & 27 & 54 \\
\hline $\begin{array}{l}\text { You will continue choosing Ha Tien to travel when you } \\
\text { have the opportunity. }\end{array}$ & 0 & 3 & 17 & 26 & 54 \\
\hline
\end{tabular}

(Source: Results from survey)

The results of Table IX show that $79 \%$ of the respondents agree and $21 \%$ disagree that tourists have considered carefully before choosing Ha Tien to visit. $81 \%$ agree and $19 \%$ disagree that the decision to choose Ha Tien for traveling is completely the right decision. $80 \%$ of the respondents agree and $20 \%$ disagree that they will continue to choose Ha Tien for traveling when given the opportunity.

\section{Analysis of Factors Affecting the Decision on Choosing Ha Tien as a Destination to Visit}

Regression analysis of factors affecting the decision on choosing Ha Tien as a destination to visit of 100 survey samples. The results of the linear regression show that the independent variables affect $66.9 \%$ of the change of the dependent variable, and the remaining $33.1 \%$ are affected by the variables out of the model and random error.

The results of ANOVA analysis show that the F statistic value is 32,393 with the significance level of 0.000 , meaning that the model has overall inferred significance.

TABLE X: REGRESSION RESULTS

\begin{tabular}{cccccc}
\hline \hline \multirow{2}{*}{ Model } & \multicolumn{2}{c}{ Unstandardized coefficients } & \multicolumn{2}{c}{$\begin{array}{c}\text { Standardized } \\
\text { coefficient }\end{array}$} & Statistical significance \\
\cline { 2 - 5 } & $\mathrm{B}$ & Std. error & Beta & 13.756 & 0.000 \\
\hline Constant & 87.833 & 6.385 & 0.096 & 2.964 & 0.004 \\
INFR & 0.104 & 0.035 & 0.117 & 0.910 & 0.365 \\
INFO & 0.128 & 0.141 & -0.447 & -3.048 & 0.003 \\
CSNSP & -0.489 & 0.160 & 1.358 & 10.491 & 0.000 \\
ENVR & 1.426 & 0.136 & -0.136 & -1.146 & 0.255 \\
PRICE & -0.143 & 0.125 & & & \\
\hline \hline
\end{tabular}

(Source: Results from survey)

The results of the regression analysis in Table $\mathrm{X}$ show that, with $1 \%$ statistical significance, independent factors including INFR, CSNSP, and ENVR have the most influence on the decision of choosing Ha Tien as a tourist destination. Based on the regression coefficient, it is also shown that the factors of landscape and environment have the strongest impact on the decision to visit places in Ha Tien, followed by the factors of cuisine and shopping, and finally the infrastructure factors.

Meaning of regression coefficients:

ENVR factor has a Beta coefficient of $1.358>0$ with a statistical significance level of 0.000 , showing that with statistical significance of $1 \%$, it can be seen that the environment and landscape factors have an influence on the decision to choose Ha Tien as a travel destination. In terms of other factors remaining 
unchanged, if increasing the environment and landscape factor by 1 point, the tourists' decision to choose places in Ha Tien to visit will increase to 1,358 .

CSNSP factor has a Beta coefficient of -0.447 with a statistical significance of 0.003 , showing that with statistical significance of $1 \%$, cuisine and shopping factors also have an influence on the decision to choose Ha Tien as a travel destination. In the condition that other factors remain constant, if increasing cuisine and shopping factor by 1 point, the tourists' decision to choose places in Ha Tien to visit increases with the regression coefficient.

INFR factor has a Beta coefficient of $0.035>0$ with a statistical significance of 0.004 , which shows that with $1 \%$ statistical significance, it can be seen that the infrastructure factor has an influence on the decision to choose $\mathrm{Ha}$ Tien as a travel destination. In terms of other factors unchanged, if increasing the infrastructure factor by 1 point, the tourists' decision to choose places in Ha Tien to visit will increase to 0.035 .

\section{CONCLUSION}

On the basis of the orientation of tourism development in the coming time, as well as from the research results and limitations of factors affecting the development of tourism in Ha Tien through the survey, the author proposes some key solutions:

\section{A. Solutions to the Investment in Building Infrastructure and Technical Facilities for Tourism Development}

According to visitors to Ha Tien, although the infrastructure system has had positive changes, especially the system of roads, ports and public transport, it has not yet met the increasing demands of tourists. To respond to the current infrastructure requirements, Ha Tien authorities should have more preferential policies to attract foreign investors to build a large international tourist port that welcomes international cruise ships. Besides, routes to tourist attractions also need to be regularly embellished.

Besides the regular maintenance of historical-cultural relics and monuments in tourist areas, Ha Tien city needs to focus on building a large-scale and modern entertainment and sports area. Moreover, it is necessary to expand more types of sea tourism such as scuba diving, fishing, adventure tourism, etc. The hotel system needs to be invested in upgrading and renewing, especially commercial hotels, modern luxury res ort hotels, following international star standards (sports complexes, fairs, conferences, entertainment facilities, etc.) to meet the tourists' accommodation needs, and restaurants need to be upgraded with local specialties, in order to increase the length of stay and spending of tourists when coming to the tourist destination. Creating favorable conditions for administrative procedures should with supporting mechanisms and policies can appeal to organizations and individuals to invest in restaurants, hotels, food courts, shopping, etc., and encourage and support tour operators to build inter-island tours (except in the places with defense factors).

Overall, the investment in infrastructure must ensure convenient circulation between tourist destinations, which is an opportunity for tourists to visit many places in a tourist period. When the tourism infrastructure meets the needs of visitors, giving visitors an interesting and healthy vacation, the decision to return to $\mathrm{Ha}$ Tien will obviously become more certain.

\section{B. Solutions to the Problem of Environmental Sanitation}

attention firstly that the local government should take measures to propagate and educate people about the importance of tourism development for the local socio-economic. The current view of tourism development is developing in a sustainable way to minimize the impacts on the landscape and tourism resources caused by the organization of tourism activities. However, the actual problem being alarmed is environmental sanitation, e.g., many companies, restaurants, hotels, food service establishments discharge domestic and production water directly into the sea; garbage is discharged along the beach; people's domestic waste is mainly stored in dug pits; corals and seagrasses are destroyed, rare marine species are not protected, etc.

To solve this problem, functional sectors and authorities at all levels need to focus on investment. The following solutions should be focused:

It is necessary to integrate the planning of environmental protection works and projects with tourist landscapes when building tourist zones, regions, and places. In fact, the planning of sectors without coordinated with each other causes situation where tourism investment projects have been completed to use while other projects (transport, electricity, waste management and treatment projects, etc.) have not been implemented. There should be planning research, investment or calling for investment in building waste treatment and recycling plants at some key tourist spots, convenient traffic or inter-district locations. Particularly remote islands with limited means of transport should equip garbage containers, make a plan to collect garbage to public landfills, classify and treat waste periodically, avoiding effects on people's health, for example by the smell of the garbage. Before issuing a tourism investment license, it is necessary to develop standards on environment and tourism landscape protection for enterprises investing in and exploiting natural tourism resources, making commitments to the implementation of these standards before beginning construction. Inspection of vulnerable natural ecological areas such as coral ecosystems, 
seagrasses, and rare marine animals should be strengthened to reduce violations. There should be a policy of sanctions and severe handling of encroachment and destruction of the environment and tourist landscapes. It is important to improve the effectiveness of management of the tourism environment; require tourist companies, restaurant services and hotels to comply with the Law on Environmental Protection; and build a collection and treatment system of wastewater and garbage following prescribed standards. Regulations on penalties for acts of causing environmental pollution; propagating and educating the community to keep the environment clean to increase the value of the environmental landscape need to be focused. Security and social order in tourist areas need to be maintained to ensure a good social environment for tourists.

Tourism businesses need to be encouraged to apply advanced technology in waste and wastewater treatment to protect the environment, and regularly organize dissemination of environmental knowledge for employees. Inefficient projects causing pollution and damage to the ecological environment, projects that do not meet the standards of environmental protection regulations, or projects that violate the district planning of tourism development should be decisively eliminated in investment to give priority to ecotourism development projects.

It is necessary to develop a strategy on environmental protection in tourist areas with specific plans for planting and protecting trees in tourist areas; encourage and guide people and tourist service establishments to collect garbage in a scientific and reasonable manner; improve the cultural level of people working in the tourism industry, linking environmental education with training programs for all participants in tourism activities; have a plan to preserve and embellish historical and cultural relics in the region in association with the conservation and exploitation of the beauty of the natural landscape.

\section{Solutions to the Culinary and Shopping}

About shopping, variety and innovation of souvenir products make visitors feel excited and tend to spend more on shopping.

Regarding cuisine, there should be a coordination between tourism management agencies, local authorities, culinary experts, food and beverage processing and supplying units in the preparation of food and drink to review, check and evaluate the conditions for hygiene assurance. On that basis, planning into culinary tourist spots with their own characteristics but still in harmony in the overall picture of tourism in Ha Tien. All classes of people should raise awareness of environmental protection and compliance with food safety and hygiene conditions through propaganda. Dishes should be promoted to become specialties, such as crab soup, Ha Tien sticky rice, Ha Tien steamed noodle soup, etc. Unique and creative culinary products should be added in tourist menu to attract visitors and create the brand of cuisine for this coastal land.

\section{CONFLICT OF INTEREST}

Authors declare that they do not have any conflict of interest.

\section{REFERENCES}

Feigenbaum, A. (1945). Measurement and Evaluation of Satisfaction Process in Retail Setting. Journal of Retailing, 57(3), 18-48.

Ha Tien Town People's Committee (2012). Tổng quan thị xã Hà Tiên - Kiên Giang. http://hatien.kiengiang.gov.vn/vivn/chinhquyen/gioithieu/tongquan.aspx.

Hai, L.T.D. (2014). The analys is of factors affecting tourists' satisfaction with service quality in Tien Giang Province. Can Tho University Journal of Science, 33, 29-37.

Hai, L.T.D., \& Giang, N.H. (2011). The analysis of factors affecting tourists' satisfaction with service quality in Kien Giang Province. Can Tho University Journal of Science, $19 \mathrm{~b}, 85-96$.

Hiep, N.X. (2016). Factors affecting tourists' decision to choose destinations: The case study of Ho Chi Minh City. Journal of Economics and Development, 27(9), 53-72.

Juran, J., \& Gryna, F. (1985). A conceptual model of service quality and its implications for future research. Journal of Marketing, $49,41-50$.

Lin, C., et al. (2007) Examining the role of cognitive and affective image in predicting choice across atural, developed, and themepark destinations. Journal of Travel Research, 46(2), 183 - 194.

Som, A.P.M., Marzuki, A., Yousefi, M., AbuKhalifeh, A.N. (2012). Factors influencing visitors' revisit behavaioral intentions: A case study of Sabah, Malaysia. International Journal of marketing studies, 4(40), 39.

Tho, N.D., et al. (2002). Nghiên cúu đo luờng các thành phần của giá trị thuơng hiệu và đo luờng chúng trong thị truờng hàng tiêu dùng tại Việt Nam. University of Economics Ho Chi Minh City.

Tra, T. (2007). Hà Tiên cảnh sắc huyền thoại. http://www.baoanhdatmui.vn/vcms/html/news_detail.php?nid=53171.

Trong, H., \& Ngoc, C.N.M. (2008). Phân tích dũ liệu nghiên cúu với SPSS.

Van Linh, T. (2012). Kiên Giang có 2 điểm du lịch tiêu biểu Đồng bằng sông Củu Long 2012. http://kiengiangvn.vn/portal/index.php?topicid=69\&pageid $=3020$. 